\title{
Active Disturbance Rejection Control for a Five-Level Cascaded H-Bridge Inverter Fed Induction Motor Sensorless Field-Oriented
}

\author{
Salma El Bourhichi (D), Abdellah Oukassi (iD), Lhoussain El Bahir (D), and Mustapha El Adnani \\ Laboratory of Systems and Applications Engineering, Cadi Ayyad University, ENSA, Marrakech 40000, Morocco \\ Correspondence should be addressed to Salma El Bourhichi; elbourhichi.salma@gmail.com
}

Received 17 March 2021; Revised 2 May 2021; Accepted 4 May 2021; Published 13 May 2021

Academic Editor: Omar Naifar

Copyright (C) 2021 Salma El Bourhichi et al. This is an open access article distributed under the Creative Commons Attribution License, which permits unrestricted use, distribution, and reproduction in any medium, provided the original work is properly cited.

\begin{abstract}
In this paper, a robust vector control sensorless based on three Active Disturbance Rejection Controllers (ADRC) for an induction motor fed by a five-level cascaded H-bridge was developed. The estimation of rotor position is achieved using a Luenberger estimator. The proposed model considers the disturbances and the inaccuracies of the system and compensates them using the extended state observer of ADRC. Moreover, a five-level cascaded H-bridge inverter is the best topology to minimize the torque ripples and to improve the current output of IMunder control. The suggested control system was simulated under different conditions using MATLAB-Simulink. The results demonstrate the effectiveness and the robustness of the proposed system against disturbances such as variations of parameters and load torque.
\end{abstract}

\section{Introduction}

Induction Motors are widely used in different industrial applications, especially in the variable speed drive applications [1], due to their robustness, high reliability, high performance, and low cost. However, the main problem of Induction Motors is related to the need for a more complex system in its control and because of nonlinear coupling between torque and flux [2].

For this reason, there are various speed control techniques available for the induction engine to solve this decoupling issue $[3,4]$. Among all methods, indirect vector control or IFOC is the most popular for achieving high efficiency $[5,6]$. Despite its safety and efficacy, IFOC has got several drawbacks such as high torque ripple, an increase in current harmonic distortion, and more disturbance problems. These disturbances can cause several problems for electrical equipment such as intense heating, abrupt shutdown of the induction motor, or even complete loss of this machinery [7].

Recently, due to their numerous benefits against the conventional two-level inverters and increasingly improved performance of the system [8], there has been an increasing interest in multilevel inverters to fed induction motor in vector control [9]. Five-level inverters (FLIs) are known for the possibility of generating five numbers of levels at the output [10]. As a result, they provide an output quasi-sinusoidal voltage with an improved harmonics spectrum. Albeit various topologies of the FLI in the literature, such as flying capacitor topology and neutral point clamped and cascaded H-bridge (HBCI) [11], the HBCI has the most potential and is used in different applications compared to other multilevel structures [12, 13]. It has a modular structure [14].

The vector control based FL-HBCI offers a better speed response and phase current [15]. It improves the torque ripples performance [16].

Nowadays, researchers have shown an increased interest in sensorless-speed controls [17] because the speed sensor is expensive and because they make control systems much more reliable, durable, robust, and cheaper. For example, they can function effectively against the variations of the machine resistances [18]. Therefore, it is necessary to have an estimator to estimate and to know the speed of the motor. For that, the common techniques to restore speed position are Model Reference Adaptive System, Fuzzy Sliding Mode 
Observer, Extended Kalman Filter, and Luenberger Observer (LO) [19]. In this study, the indirect vector control is developed for induction motor fed by FL-HBCI, using LO to estimate the speed position.

Proportional-integral (PI) is a conventional regulator used in different industrial applications, especially applications of induction motor drives, because of its easy implementation and simple structure [20]. However, the performance of the PI controller-based-control system suffers from various problems: perceptual high sensitivity against disturbing and loud noises and the excessive loss of efficiency due to superficial regulation [21]. Moreover, it requires a long recovery period when disturbances occur [22].

In order to overcome these drawbacks, researchers developed a very robust controller called Active Disturbance Rejection Controller (ADRC). It was firstly proposed in 1998 by Han [23] and was later developed by Gao and many researchers $[20,24]$. It can reduce output noise and problems due to parameter uncertainty and disturbances. It can improve the robustness of the system against external disturbances and changes in parameters $[25,26]$. For that, the PI controllers could be replaced by the ADRC controllers.

The major contribution of this paper is connected to suggesting a robust vector control sensorless system based on three Active Disturbance Rejection Controllers (ADRC) for an induction motor fed by a five-level cascaded $\mathrm{H}$-bridge. The speed estimator is based on Luenberger Observer. To achieve good robustness, the accuracy and the rapidity of responses are expected.

A comparative study is provided with the PI controller applied for FL-HBCI, the simulation results are obtained using MATLAB-Simulink, to verify the performance, to evaluate the robustness of the suggested system, and to investigate its efficiency under different conditions.

The overall structure of the paper takes the form of six sections, including this introductory section. Section 2 is devoted to the models used in this study. Section 3 presents the adaptive scheme for the Luenberger estimator. Section 4 presents the motor commands, focusing on the application of the ADRC controller to the FLI-HBC scheme feeding sensorless-speed. Section 5 presents and discusses the results of the current study. The last section draws conclusions from the study.

\section{Models of the System}

2.1. Model of Induction Motor. The magnetizing flux equations of an induction motor in a reference two-phase frame $(d, q)$ are shown:

$$
\left\{\begin{array}{l}
\frac{\mathrm{d} \phi_{d r}}{\mathrm{~d} t}=\frac{L_{m}}{L_{r}} R_{r} i_{d s}-\frac{R_{r}}{L_{r}} \phi_{d r}+\left(\omega_{s}-\omega\right) \phi_{q r} \\
\frac{\mathrm{d} \phi_{q r}}{\mathrm{~d} t}=\frac{L_{m}}{L_{r}} R_{r} i_{q s}-\frac{R_{r}}{L_{r}} \phi_{q r}+\left(\omega-\omega_{s}\right) \phi_{d r} .
\end{array}\right.
$$

The stator currents of the induction motor in two-phase voltage $\left(V_{d s}, V_{q s}\right)$ can be written as follows:

$$
\begin{aligned}
& \frac{\mathrm{d} i_{d s}}{\mathrm{~d} t}=-\left(\frac{1}{T_{s} \sigma}\right) i_{d s}-\left(\frac{L_{m}}{L_{r} L_{s} \sigma}\right) \frac{\mathrm{d} \phi_{r}}{\mathrm{~d} t}+\left(\frac{1}{L_{s} \sigma}\right) V_{d s}, \\
& \frac{\mathrm{d} i_{q s}}{\mathrm{~d} t}=-\left(\frac{1}{T_{s} \sigma}\right) i_{q s}-\left(\frac{L_{m} \omega_{s}}{L_{r} L_{s} \sigma}\right) \phi_{r}+\left(\frac{1}{L_{s} \sigma}\right) V_{q s},
\end{aligned}
$$

where

$$
\begin{aligned}
T_{s} & =\frac{L_{s}}{R_{s}}, \\
\sigma & =1-\frac{L_{m}^{2}}{L_{r} L_{s}} .
\end{aligned}
$$

The electromagnetic torque $\left(C_{\text {elm }}\right)$ and the rotor speed $(\Omega)$ of the induction motor in the $(d-q)$ axis are given as follows:

$$
\begin{aligned}
\frac{\mathrm{d} \Omega}{\mathrm{d} t} & =-\left(\frac{f_{r}}{J}\right) \Omega-\left(\frac{1}{J}\right) C_{r}+\frac{1}{J} C_{e l m}, \\
C_{e l m} & =p \frac{L_{m}}{L_{r}}\left(\phi_{r d} i_{q s}-i_{d s} \phi_{r q}\right),
\end{aligned}
$$

where $\phi_{r}$ is the rotor flux magnitude, $p$ is the number of poles, $i_{d s}, i_{q s}$ are stator current of $d$ and $q$ axis, $J$ is the moment of inertia, $\omega_{s}$ is the synchronous speed, and $C_{r}$ $(\mathrm{Nm})$ is the load torque.

2.2. Model of Indirect-Field-Oriented Control. The model of indirect vector control was initially invented by Blaschke in 1972 [27]. It is based on decoupling control.

Clarke transformation and Park transformation are used to achieve the DC machine output required [3].

For decoupling control, the fluxes equations are given by

$$
\left\{\begin{array}{l}
\phi_{d r}=\phi_{r}=c t e \\
\phi_{q r}=0
\end{array}\right.
$$

Equations (1) and (6) become

$$
\left\{\begin{array}{l}
\phi_{r}=L_{m} i_{d s}, \\
C_{e l m}=K i_{q s} .
\end{array}\right.
$$

While $K=p\left(L_{m} / L_{r}\right) \phi_{r}=$ cte, $L_{m}$ is mutual inductance.

2.3. FL-HBCI Topology. FLIs perform better than the threelevel and the two-level inverters. They provide a harmonic reduction and decrease the losses for motor drives [28].

There are different structures of the FLI, but the HBCI is the preferable one due to its several advantages over other FLIs. It does not need many components, and it does not have fluctuation in neutral point voltage problems compared to FL-Diode Clamped and FL-flying capacitors inverters [29].

A FL-HBCI simplified circuit is presented in Figure 1. It has a modular structure. It comprises two separate DC voltages $(\mathrm{T})$ in every phase; five output voltage levels can be obtained $+2 \mathrm{~T},+\mathrm{T}, 0,-\mathrm{T}$, and $-2 \mathrm{~T}$. 
The HCB-FLI produces an output voltage equal to $+2 \mathrm{~T}$ when $\mathrm{O}_{3}, \mathrm{O}_{2}, \mathrm{O}_{7}$, and $\mathrm{O}_{6}$ are switched ON. $+\mathrm{T}$ can be obtained when $\mathrm{O}_{3}, \mathrm{O}_{2}, \mathrm{O}_{7}$, and $\mathrm{O}_{8}$ are switched $\mathrm{ON}$, whereas 0 can be attained when $\mathrm{O}_{3}, \mathrm{O}_{2}, \mathrm{O}_{8}$, and $\mathrm{O}_{5}$ are on ON. $-\mathrm{T}$ can be obtained when $\mathrm{O}_{3}, \mathrm{O}_{8}, \mathrm{O}_{5}$, and $\mathrm{O}_{4}$ are switched ON. $-2 \mathrm{~T}$ can be achieved when $\mathrm{O}_{8}, \mathrm{O}_{5}, \mathrm{O}_{4}$, and $\mathrm{O}_{1}$ are turned $\mathrm{ON}$.

In-phase disposition Sinusoidal pulse-width modulation (IP-SPWM), where all carrier waveforms are in phase, is used to select the switches of the inverter. Its principle is based on the intersection of the sinusoidal reference signal with the triangular carrier waves.

\section{Adaptive Scheme for Luenberger Estimator}

There are different types of strategies to estimate the parameters of an IM. The Luenberger Observer (LO) is the most popular one due to its simplicity and precision [30].

The principle of the LO method is based on the statevariables model of the induction motor. The measured values (stator voltage and currents) are compared to the estimated values to obtain errors by using an adaptive model. Then, the output error is multiplied by the PI controller to generate the estimated speed.

The LO is designed as follows:

$$
\left\{\begin{array}{l}
\ddot{x}=A \bar{x}+B u+L(y-\bar{y}), \\
\widehat{y}=C \bar{x},
\end{array}\right.
$$

where $L$ is the Luenberger gain.

However,

$$
\begin{aligned}
& \bar{x}=\left(\begin{array}{llll}
\hat{i}_{\alpha s} & \hat{i}_{\beta s} & \hat{\varphi}_{\alpha r} & \hat{\varphi}_{\beta r}
\end{array}\right)^{T}, \\
& \bar{y}=\left(\begin{array}{cc}
\hat{i}_{\alpha s} & \hat{i}_{\beta s}
\end{array}\right) \text {, } \\
& A=\left(\begin{array}{cccc}
p_{11} & 0 & p_{13} & p_{14} \omega_{r} \\
0 & p_{11} & p_{14} \omega_{r} & p_{13} \\
p_{31} & 0 & p_{33} & -\omega_{r} \\
0 & p_{31} & \omega_{r} & p_{33}
\end{array}\right), \\
& B=\left(\begin{array}{cccc}
b_{11} & 0 & 0 & 0 \\
0 & b_{11} & 0 & 0
\end{array}\right), \\
& C=\left(\begin{array}{llll}
1 & 0 & 0 & 0 \\
0 & 1 & 0 & 0
\end{array}\right) \text {, } \\
& L=\left(\begin{array}{cccc}
\lambda_{11} & \lambda_{12} & \lambda_{13} & \lambda_{14} \\
-\lambda_{12} & \lambda_{11} & -\lambda_{14} & \lambda_{13}
\end{array}\right) \text {, }
\end{aligned}
$$

with

$$
\begin{aligned}
p_{11} & =-\frac{1}{\sigma}\left(\frac{1}{T_{s}}+\frac{1-\sigma}{T_{r}}\right), \\
p_{13} & =\frac{L_{m}}{\sigma \cdot L_{r} \cdot L_{s} \cdot T_{r}}, \\
p_{14} & =\frac{L_{m}}{\sigma \cdot L_{s} \cdot L_{r}}, \\
p_{31} & =\frac{L_{m}}{T_{r}}, \\
p_{33} & =-\frac{1}{T_{r}}, \\
b_{11} & =\frac{1}{\sigma L_{s}}, \\
T_{r} & =\frac{L_{r}}{R_{r}}, \\
\sigma & =1-\frac{L_{m}^{2}}{L_{r} L_{s}}, \\
\lambda_{11} & =(1-k)\left(p_{11}+p_{33}\right), \\
\lambda_{12} & =(1-k) \omega_{r} \\
\lambda_{13} & =\left(1-k^{2}\right)\left(p_{31}+\frac{p_{11}}{p_{14}}\right)-\frac{\lambda_{11}}{p_{14}} \\
\lambda_{14} & =\frac{\omega_{r}(1-k)}{p_{14}} .
\end{aligned}
$$

To ensure stability, the Lyapunov function is used and given by [31]

$$
V=e^{T} e+\frac{\left(\Delta \omega_{r}\right)^{2}}{\rho}
$$

with $\rho$ being a positive constant coefficient. $e=x-\widehat{x}$ is the estimation error vector of the induction motor and LO.

$$
\Delta \omega=\omega_{r}-\widehat{\omega}_{r} .
$$

The time derivate of $V$ is expressed as

$$
\frac{\mathrm{d} V}{\mathrm{~d} t}=\frac{\mathrm{d} e^{T}}{\mathrm{~d} t} e+e^{T} \frac{\mathrm{d} e}{\mathrm{~d} t}+\frac{1}{\rho} \frac{\mathrm{d}\left(\Delta \omega_{r}\right)^{2}}{\mathrm{~d} t},
$$

which should be negative.

Thus, equation (14) is developed as [31]

$$
\frac{\mathrm{d} V}{\mathrm{~d} t}=e^{T}\left[(A-L C)^{T}+(A-L C)\right] e+2 \Delta \omega_{r} p_{14}\left(e_{\alpha s} \widehat{\varphi}_{\beta r}-e_{\beta s} \widehat{\varphi}_{\alpha r}\right)-\frac{2 \Delta \omega_{r}}{\rho} \frac{\mathrm{d} \widehat{\omega}_{r}}{\mathrm{~d} t},
$$

where 


$$
\begin{aligned}
& e_{\alpha s}=i_{\alpha s}-\hat{i}_{\alpha s}, \\
& e_{\beta s}=i_{\beta s}-\hat{i}_{\beta s} .
\end{aligned}
$$

The expression $e^{T}\left[(A-\mathrm{LC})^{T}+(A-\mathrm{LC})\right] e$ is always negative (since the imposed eigenvalues of the LO) [31].

The last two terms can be set to zero because they are weak compared to the first [31].

$$
2 \Delta \omega_{r} p_{14}\left(e_{\alpha s} \widehat{\varphi}_{\beta r}-e_{\beta s} \widehat{\varphi}_{\alpha r}\right)-2\left(\frac{\Delta \omega_{r}}{\rho}\right) \frac{\mathrm{d} \widehat{\omega}_{r}}{\mathrm{~d} t}=0 .
$$

Thus,

$$
\widehat{\omega}_{r}=\rho p_{14} \int\left(e_{\alpha s} \widehat{\varphi}_{\beta r}-e_{\beta s} \widehat{\varphi}_{\alpha r}\right) \mathrm{d} t
$$

To improve the accuracy of the estimation, many researchers have proposed a PI-type adaptation mechanism. The following expression of the estimated speed is obtained:

$$
\widehat{\omega}_{r}=\left(K_{p}+\frac{K_{i}}{s}\right)\left(e_{\alpha s} \widehat{\varphi}_{\beta r}-e_{\beta s} \widehat{\varphi}_{\alpha r}\right) \text {, }
$$

where $K_{p}$ and $K_{i}$ are positive constants which can be adjusted.

\section{Motor Commands}

4.1. Active Disturbance Rejection Controller. The IFOC for a FL-HBCI fed induction motor sensorless system can be affected by different internal (variation of resistance) and external perturbations (load torque, variation of speed). For that, ADRC is used as a robust control approach. Its principle is that all failures, disturbances, and uncertainties are handled in real-time as "total perturbation" through being calculated and compensated [25, 32]. It can estimate the whole perturbation as an extended state of the system by the introduction of the extended state observer (ESO).

For our case, the system is of the first order. In general, the canonical form of the first-order system is [33]

$$
y=f(y, \varepsilon, t)+b_{0} u
$$

where $u$ is the input variable; $y$ is the output variable, and $b_{0}$ is the constant. $\varepsilon$ represents the whole of external and internal disturbances

Equation (20) can be written following in the state-space form as:

$$
\left\{\begin{array}{l}
\dot{x}=A x+b_{0} B u+E h \\
y=C x
\end{array}\right.
$$

with

$$
\begin{aligned}
& A=\left(\begin{array}{ll}
0 & 1 \\
0 & 0
\end{array}\right), \\
& E=\left(\begin{array}{l}
0 \\
1
\end{array}\right), \\
& B=\left(\begin{array}{l}
1 \\
0
\end{array}\right), \\
& C=\left(\begin{array}{l}
1 \\
0
\end{array}\right), \\
& x=\left(\begin{array}{l}
x_{1} \\
x_{2}
\end{array}\right), \\
& h=\dot{f} .
\end{aligned}
$$

The ESO can be presented by the following equation:

$$
\left\{\begin{array}{l}
\dot{x}_{1}=b_{0} u+x_{2}, \\
\dot{x}_{2}=\dot{f}, \\
y=x_{1} .
\end{array}\right.
$$

The linear ESO can be expressed as

$$
\left\{\begin{array}{l}
\dot{z}=A z+b_{0} B u+L(y-\widehat{y}) \\
\hat{y}=C z
\end{array}\right.
$$

where $L$ is the observer gain vector:

$$
L=\left(\begin{array}{l}
\eta_{1} \\
\eta_{2}
\end{array}\right)=\left(\begin{array}{c}
2 \omega_{0} \\
\omega_{0}^{2}
\end{array}\right)
$$

with $\omega_{0}$ being the bandwidth of the observer. It is determined by the pole placement, to ensure the fast and good output, with a minimum of noise [34].

An ADRC well-tuned can compensate the total of disturbance. The control law is defined by

$$
u=\frac{u_{0}-z_{2}}{b_{0}} \text {. }
$$

with $z_{2}$ being a correct estimation of " $f$ " and $z_{1}$ a correct estimation of " $y$ ".

Equation (20) becomes

$$
\left\{\begin{array}{l}
\dot{y}=u_{0}+\left(f-z_{2}\right) \simeq u_{0}, \\
u_{0}=k_{p}\left(g-z_{1}\right)
\end{array}\right.
$$

where $g$ is the reference input signal.

Figure 2 shows the structure of an ADRC. It consists of three blocks.

In our case, equations (2)-(4) can be rearranged to be written in the canonical form of ADRC. It can be described by the following equations: 


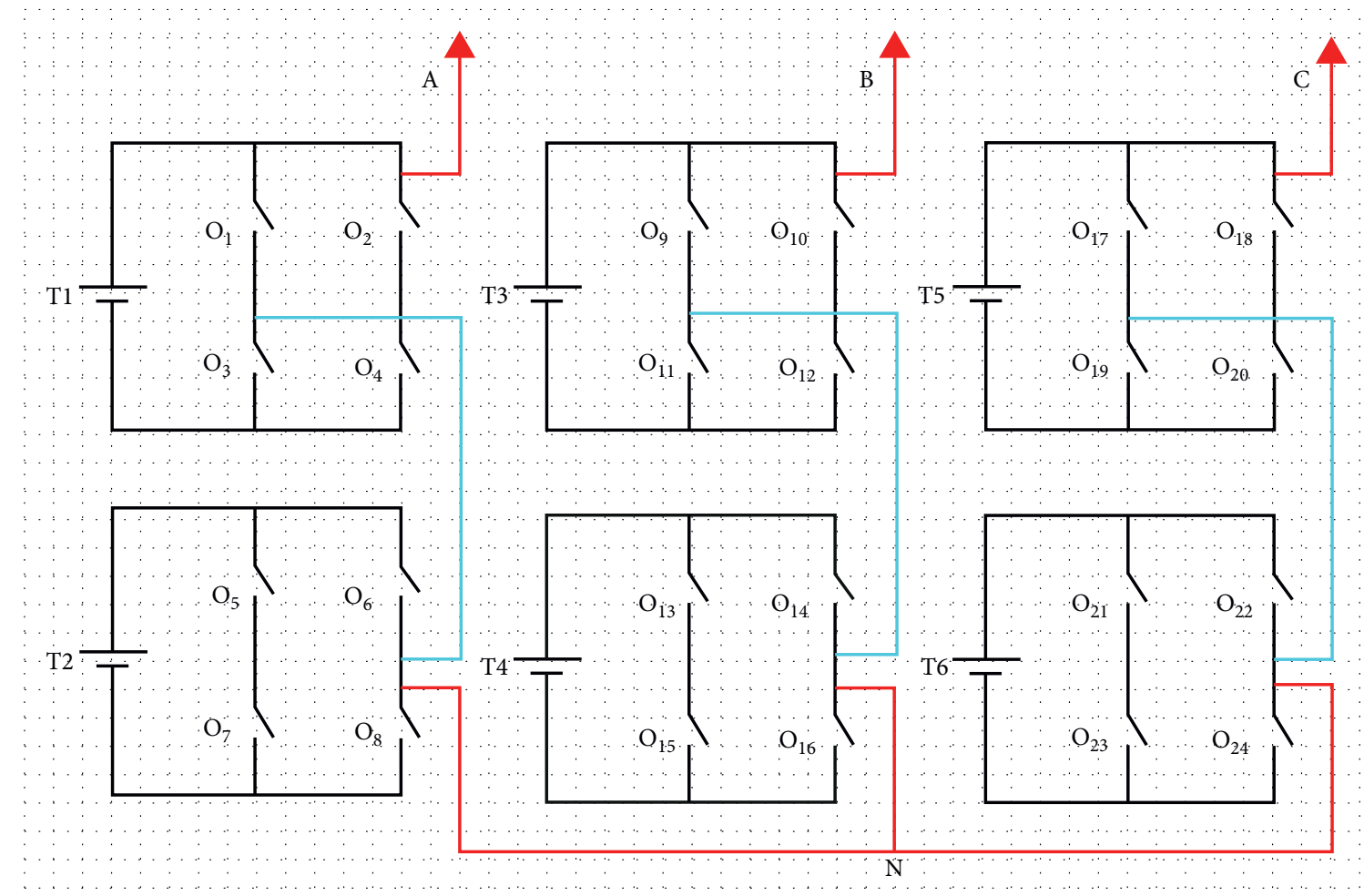

Figure 1: Structure of conventional FL cascaded H-bridge.

$$
\left\{\begin{array}{l}
\frac{\mathrm{d} i_{d s}}{\mathrm{~d} t}=f_{d}\left(i_{d s}, \varepsilon, t\right)+b_{0} u_{d}(t), \\
\frac{\mathrm{d} i_{q s}}{\mathrm{~d} t}=f_{q}\left(i_{q s}, \varepsilon, t\right)+b_{0} u_{q}(t), \\
\frac{\mathrm{d} \Omega}{\mathrm{d} t}=f_{\Omega}(\Omega, \varepsilon, t)+b_{0 \omega} u(t),
\end{array}\right.
$$

with

$$
\begin{aligned}
& b_{0}=\frac{1}{L_{s} \sigma}, \\
& b_{0 \omega}=\frac{1}{J}, \\
& u_{d}=V_{d s}, \\
& u_{q}=V_{q s}, \\
& u=C_{e l m},
\end{aligned}
$$

where $b_{0}$ and $b_{0 \omega}$ are the known part in the controller tuning, when selecting the adequate response time. The parameters of the ADRC can be found easily.

Figure 3 shows the ADRC-IFOC scheme of the FLI-HBC feeding induction motor sensorless.
4.2. PI Controller. Figure 4 shows the PI controllers applied on the FLI-HBC fed induction motor sensorless.

The parameters of the PI controllers have been adjusted by a method based on a criterion giving a better compromise between the response time and the overshoot.

\section{Simulation Results and Discussion}

The proposed ADRC-IFOC of FL-HCBI fed induction motor sensorless scheme with three ADRC controllers (speed and currents controllers) is presented in Figure 4. The outputs of the ADRC flow and torque controllers are uncoupled, to ensure the decoupling of the IFOC approach. Therefore, three references are generated for the SPWM modulator. The induction motor receives input signals from the FL-HCB inverter. The speed is estimated using the Luenberger estimator.

The simulation was conducted on the platform MATLAB-Simulink. The numerical parameters of the induction motor are provided in Table 1.

To evaluate the performances of the suggested ADRC control for FL-HCBI fed IM sensorless, different conditions are applied. Therefore, the reference speed value is maintained to $\mathrm{A} 7 \mathrm{~B} 7=\left[\begin{array}{lll}90 & 130 & 50\end{array}\right] \mathrm{rad} / \mathrm{s}$ at $\left\{\begin{array}{lll}0 & 2 & 6\end{array}\right\} \mathrm{s}$. In addition, the load disturbance torque is applied at $\left\{\begin{array}{l}3 \\ 5\end{array} 7.58 .5\right\}$ s with the values [ $5-56-6]$ N.m. The suggested system is compared to the control for FL-HCBI fed IM sensorless based on the PI.

Initially, the simulation result of the output voltage for FL-HBCI on ADR-IFOC sensorless is obtained and shown in Figures 5 and 6. 


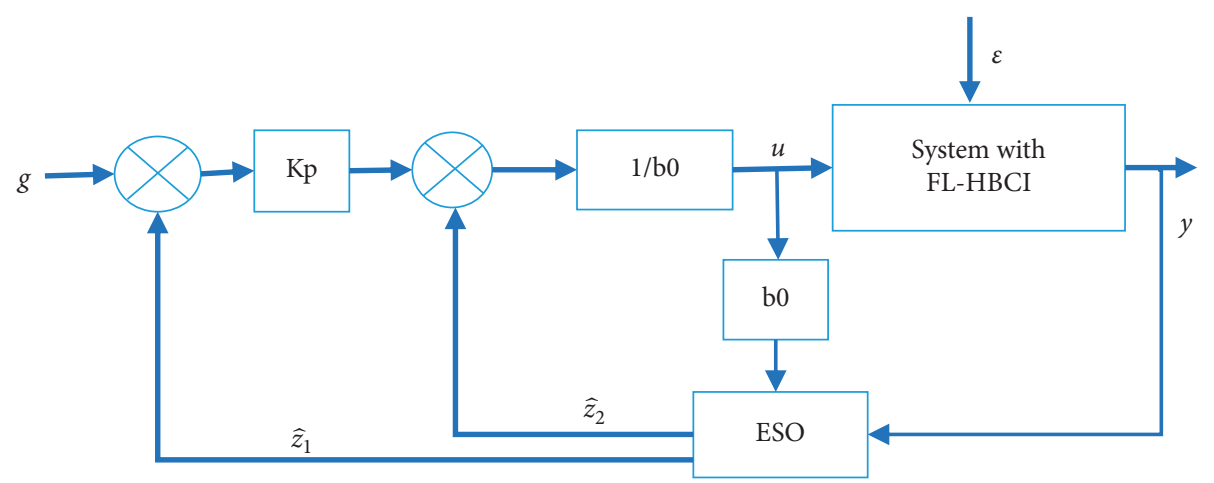

Figure 2: The block ADRC controller of a first order.

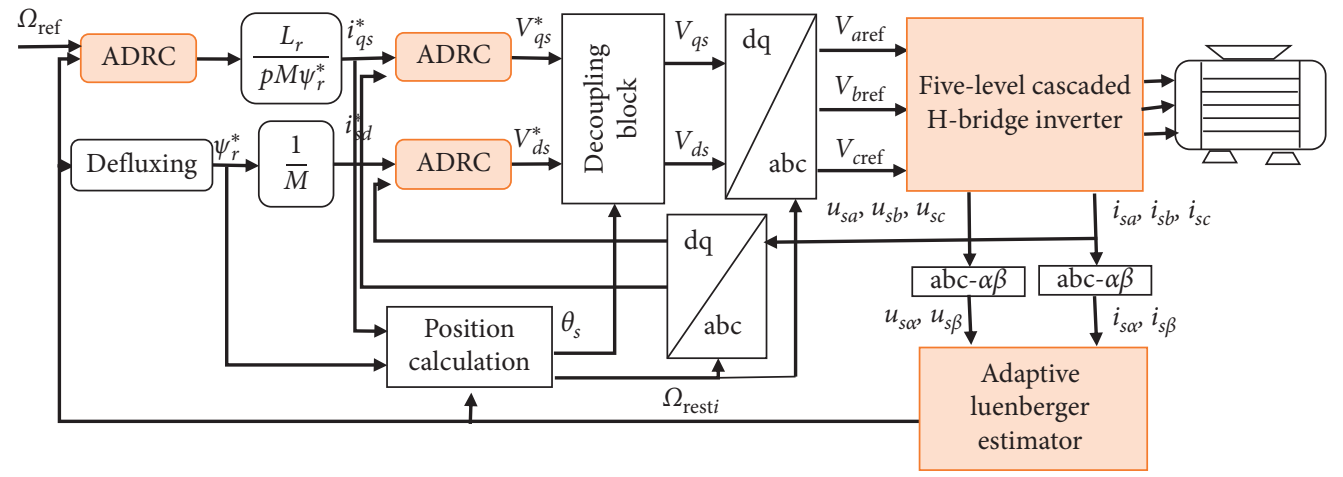

Figure 3: The ADRC-IFOC scheme of the FL-HBCI fed induction motor sensorless.

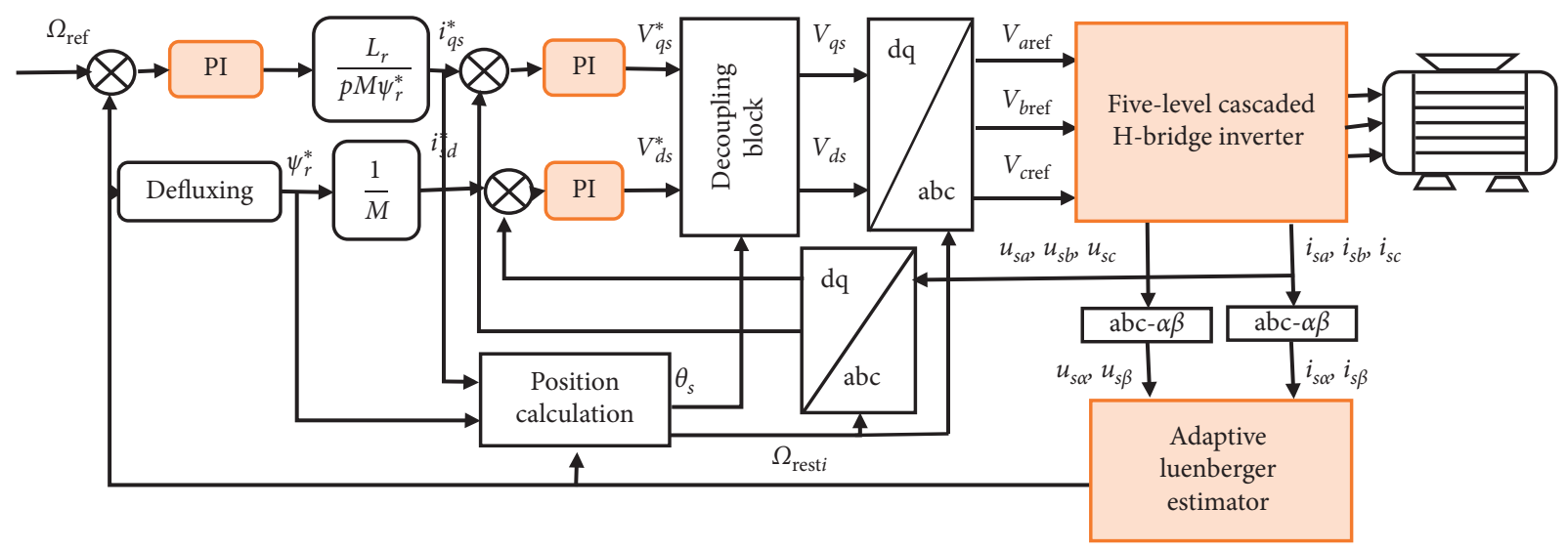

Figure 4: The PI-IFOC scheme of the FL-HBCI fed induction motor sensorless.

5.1. Speed Variation and Load Torque Variation. Figure 7 shows the output of rotor speed of both systems; they successfully operated. From the figure, it can be seen that the response speed with ADRC follows more quickly the reference speed, despite the variation of torque, compared to the output speed with PI.

It is clear in Figure 8 that the torque performance of the system with ADRC is better than that with the use of the classical PI controller. Indeed, when the speed reference steps up from $90 \mathrm{rad} / \mathrm{s}$ to $130 \mathrm{rad} / \mathrm{s}$ at $2 \mathrm{~s}$ and at $6 \mathrm{~s}$, we notice that the response torque with ADRC rejects rapidly the perturbation.

Figure 9 portrays the result of direct current for both of the systems. It is observed that ripples are more reduced with ADRC than with PI.

Figures 10 and 11 indicate the result of stator phase current for PI and ADRC, respectively, applied to the suggested system.

Moreover, the error of speed achieved both with the classic PI and with ADRC is shown in Figure 12. It is made 
TABLE 1: Three-phase IM parameters.

\begin{tabular}{lcc}
\hline Parameter & Symbol & Value \\
\hline Principal machine inductance & $L_{s}$ & $0,3973 \mathrm{H}$ \\
Seconder machine inductance & $L_{r}$ & $0,3558 \mathrm{H}$ \\
Stator resistance & $R_{r}$ & 5.4 \\
Mutual inductance & $L_{m}$ & $0,39 \mathrm{H}$ \\
Number of pole pairs & $P$ & 2 \\
Inertia moment & $J$ & $0,02 \mathrm{~kg} \cdot \mathrm{m}^{2}$ \\
Viscous friction coefficient & $f_{v}$ & $0,0025 \mathrm{~N} \cdot \mathrm{m} . \mathrm{s} / \mathrm{rad}$ \\
Power & $P$ & $1 \mathrm{kw}$ \\
\hline
\end{tabular}

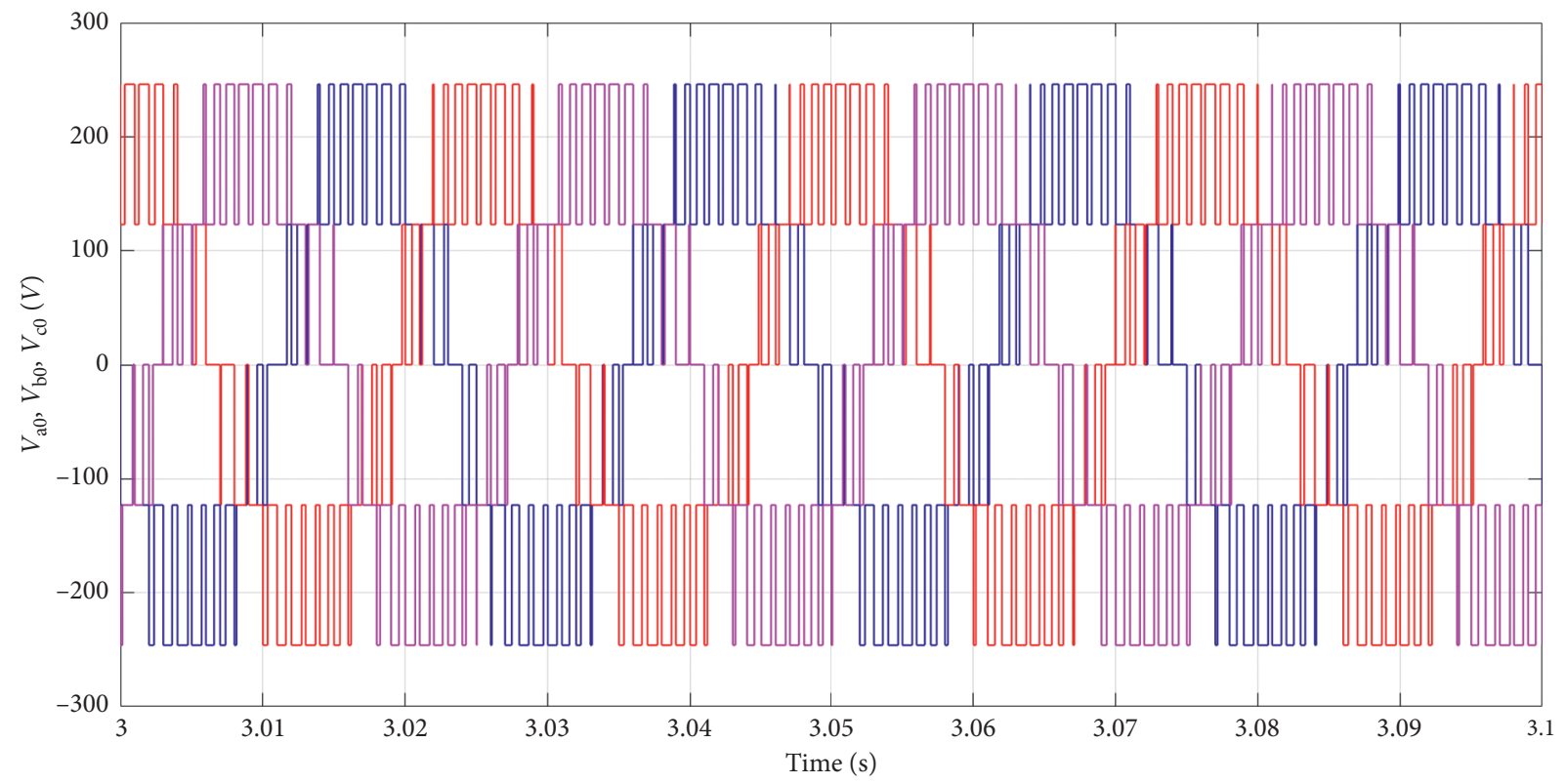

FIgURe 5: Voltage waveform for FL-HBCI on ADR-IFOC (zoom of $V_{a 0} ; V_{b 0} ; V_{c 0}$ ).

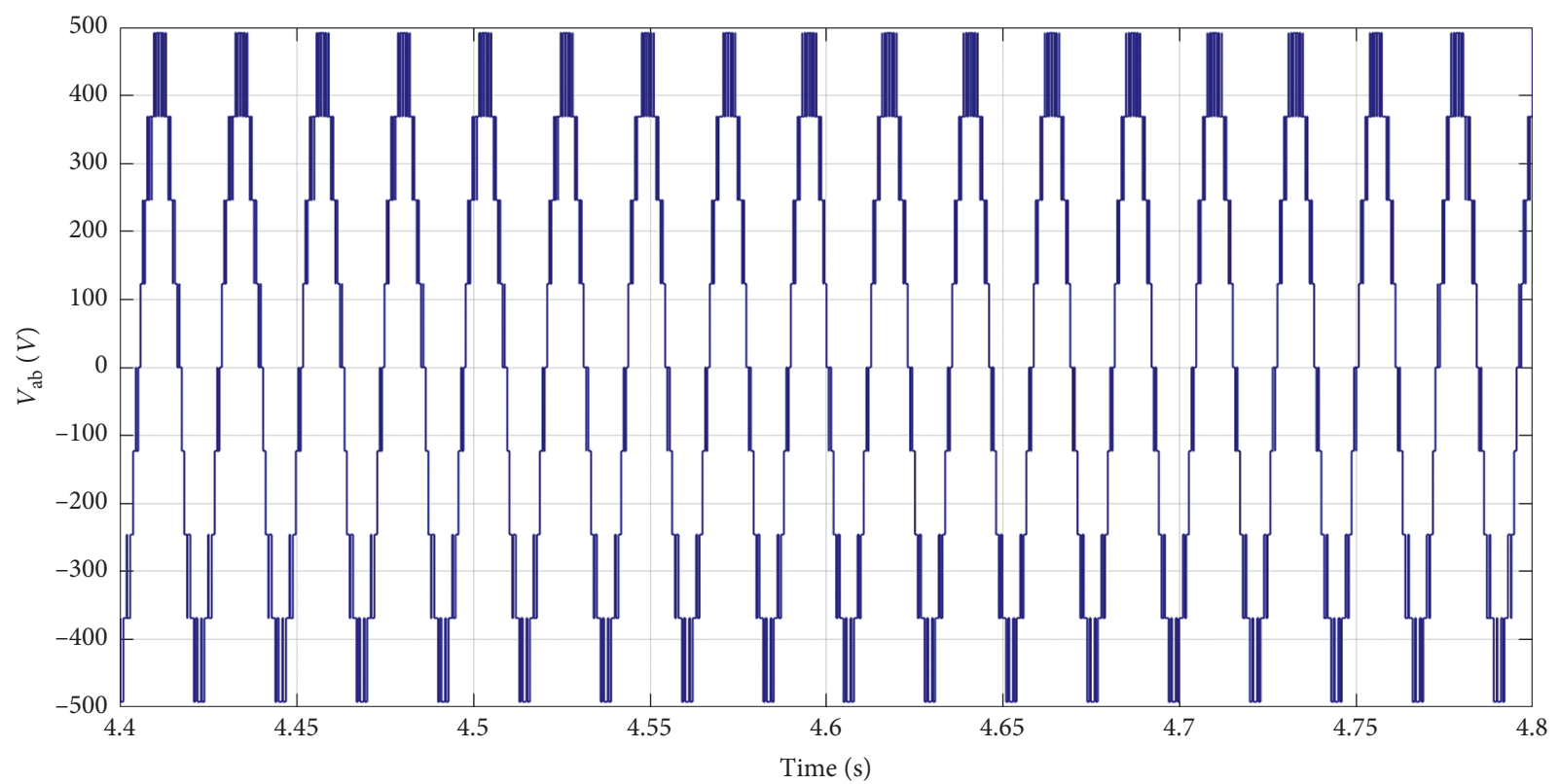

Figure 6: Voltage waveform for FL-HBCI on ADR-IFOC (zoom of $V_{a b}$ ). 


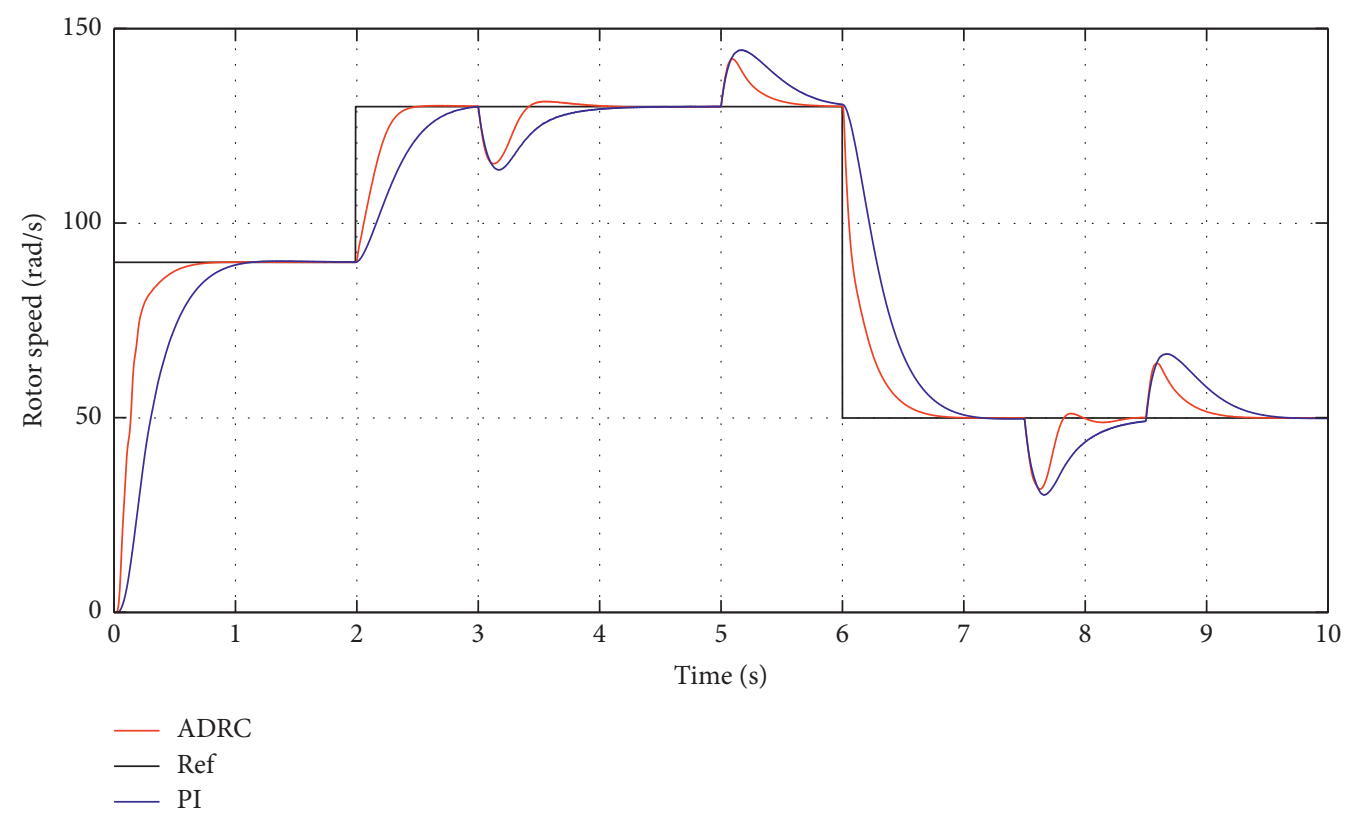

FIgURE 7: The result of rotor speed of the FL-HBCI fed induction motor sensorless under torque variation.

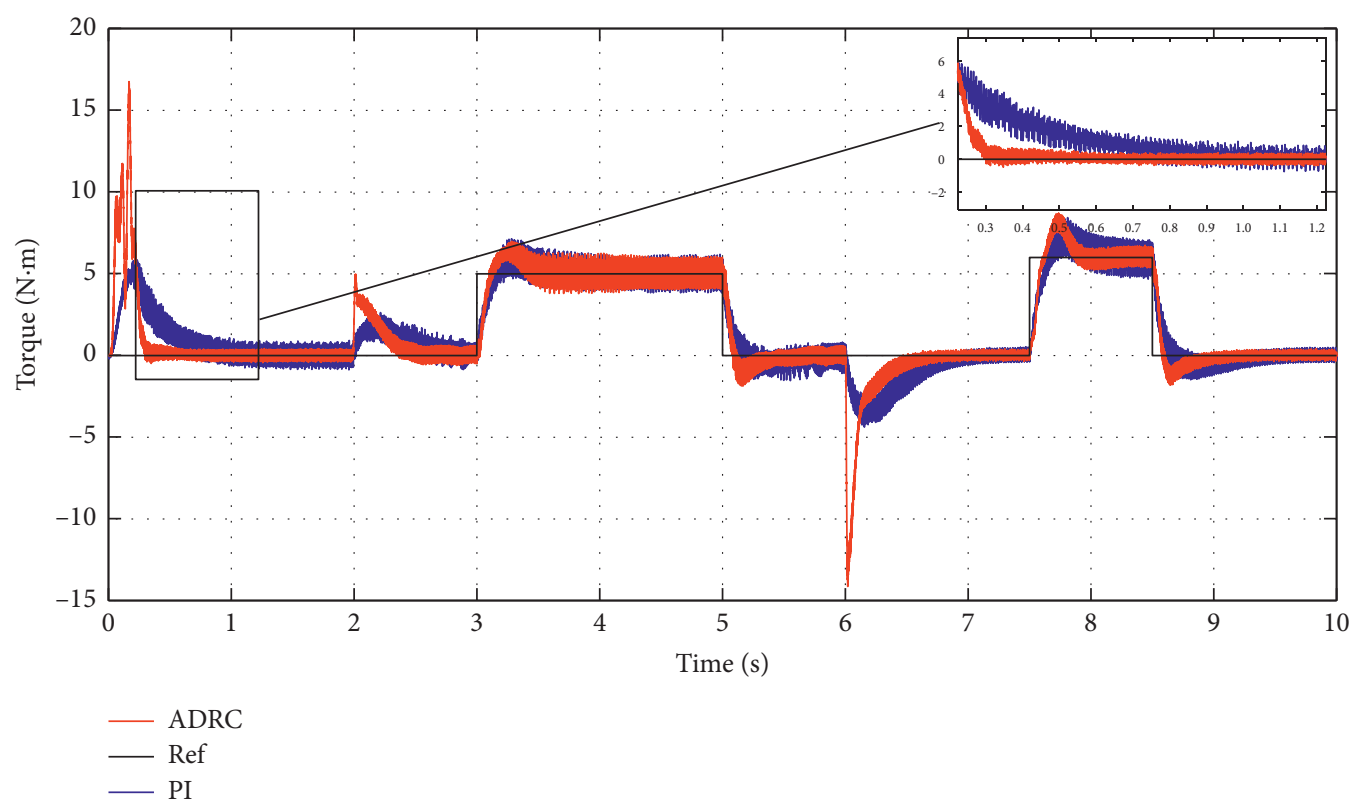

FIGURE 8: The result of torque for PI and ADRC used in the sensorless control IM fed by FL-HBCI.

clear that the biggest tracking error of speed occurs for the system with PI.

From the simulation results, it can be seen that the FLHCBI IM obtains satisfactory performance in sensorless control with a minimum of ripples.

From the comparison, both systems give satisfactory results; the torque ripples have minimized with the use of FL-HCBI.

The system with PI requires more time to settle down when there is a variation of reference speed or application of disturbance. Moreover, some ripples are visible more than the system with ADRC. However, the system with ADRC handles the disruption better than PI. It can return to the steady state rapidly after sudden changes (such as the application of load torque). The ADRC improves system resistance against disturbances; therefore, it increases the ruggedness of the suggested system.

5.2. Resistance Variation and Load Torque Variation. For induction motor control system, the resistances of IM may suddenly vary, due to temperature variation with the operation time of IM. For that, the rotor and stator resistances parameters are selected, to evaluate the robustness of both systems under parameters variation and in worst cases. 


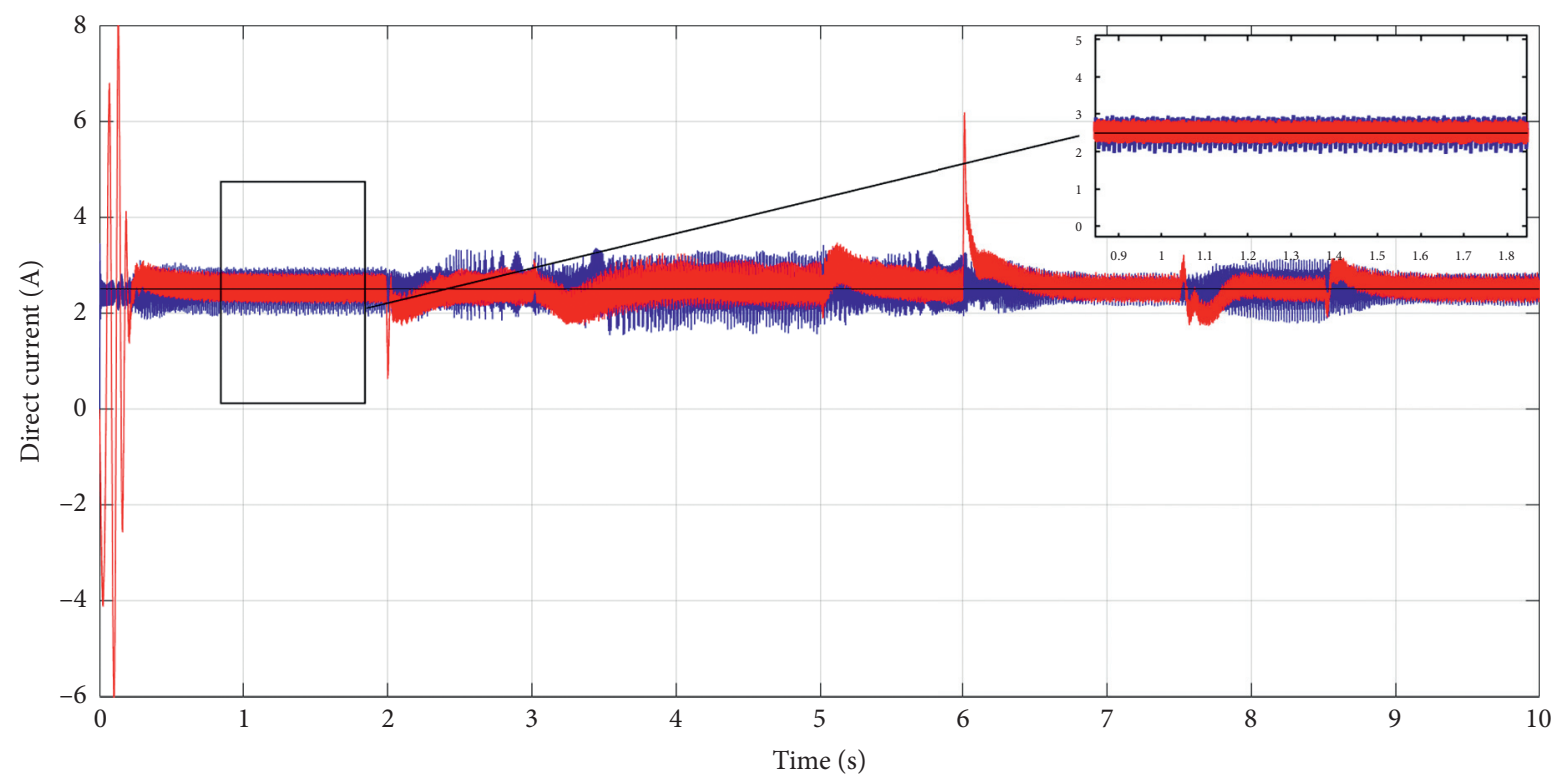

ADRC

- Ref

— PI

FIgure 9: The result of direct current for PI and ADRC used in the sensorless control IM fed by FL-HBCI.

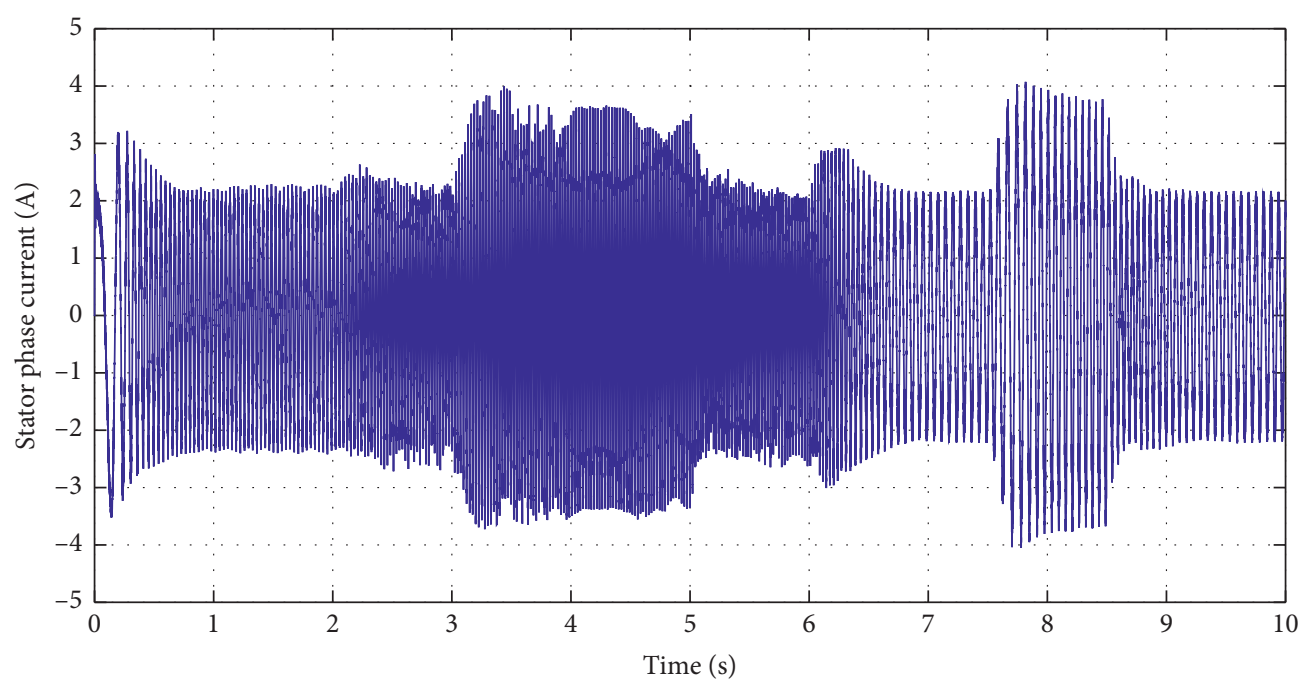

FIGURE 10: The result of stator phase current for PI used in the sensorless control IM fed by FL-HBCI.

Firstly, the value of the rotor resistance is increased by $100 \%$ from its nominal resistance.

Figure 13 shows the simulation results of the ADRC and PI systems, with the same response time, under rotor resistance variation.

Figure 14 shows the simulation results of the ADRC and PI systems, with the same response time, under stator resistance variation. Its value is increased by $50 \%$ from its nominal stator value.

Figures 13 and 14 indicate that when the motor reaches $90 \mathrm{rad} / \mathrm{s}$. At $0.6 \mathrm{~s}$, the system with ADRC follows smoothly the reference speed despite the variation of resistance. Nevertheless, the system with PI has an overshoot. When the load torque increases suddenly from 


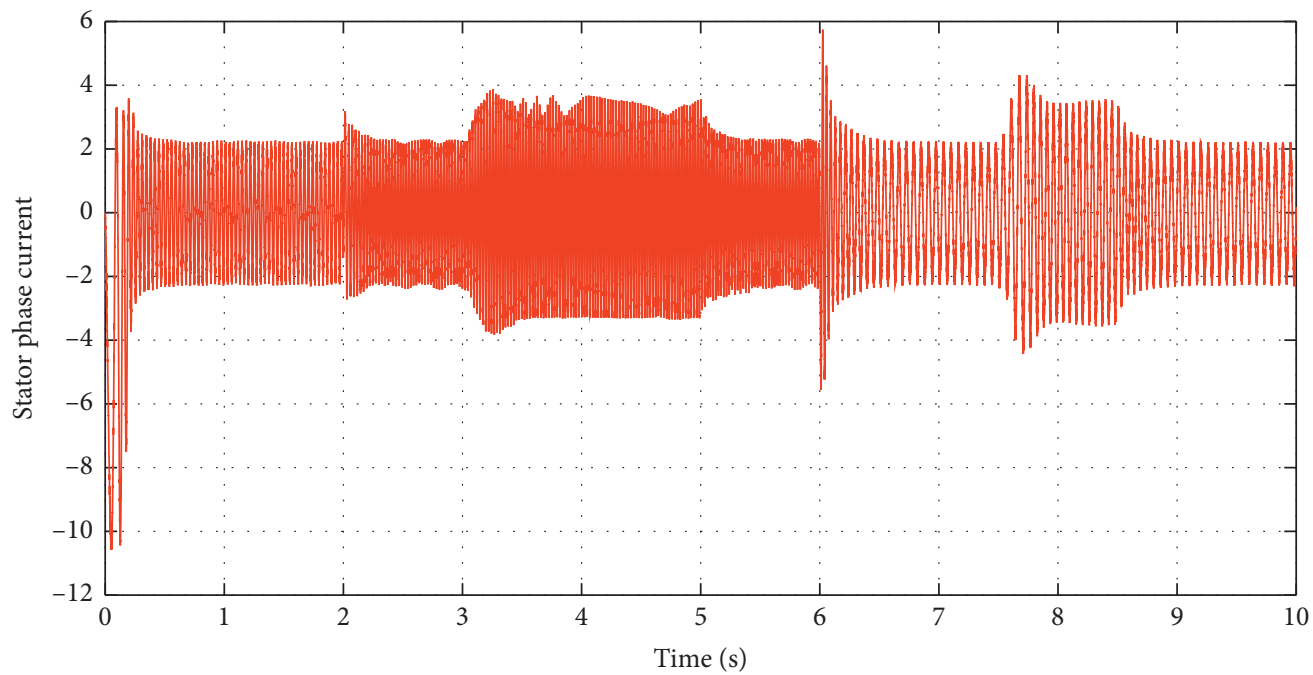

Figure 11: The result of stator phase current for ADRC used in the sensorless control IM fed by FL-HBCI.

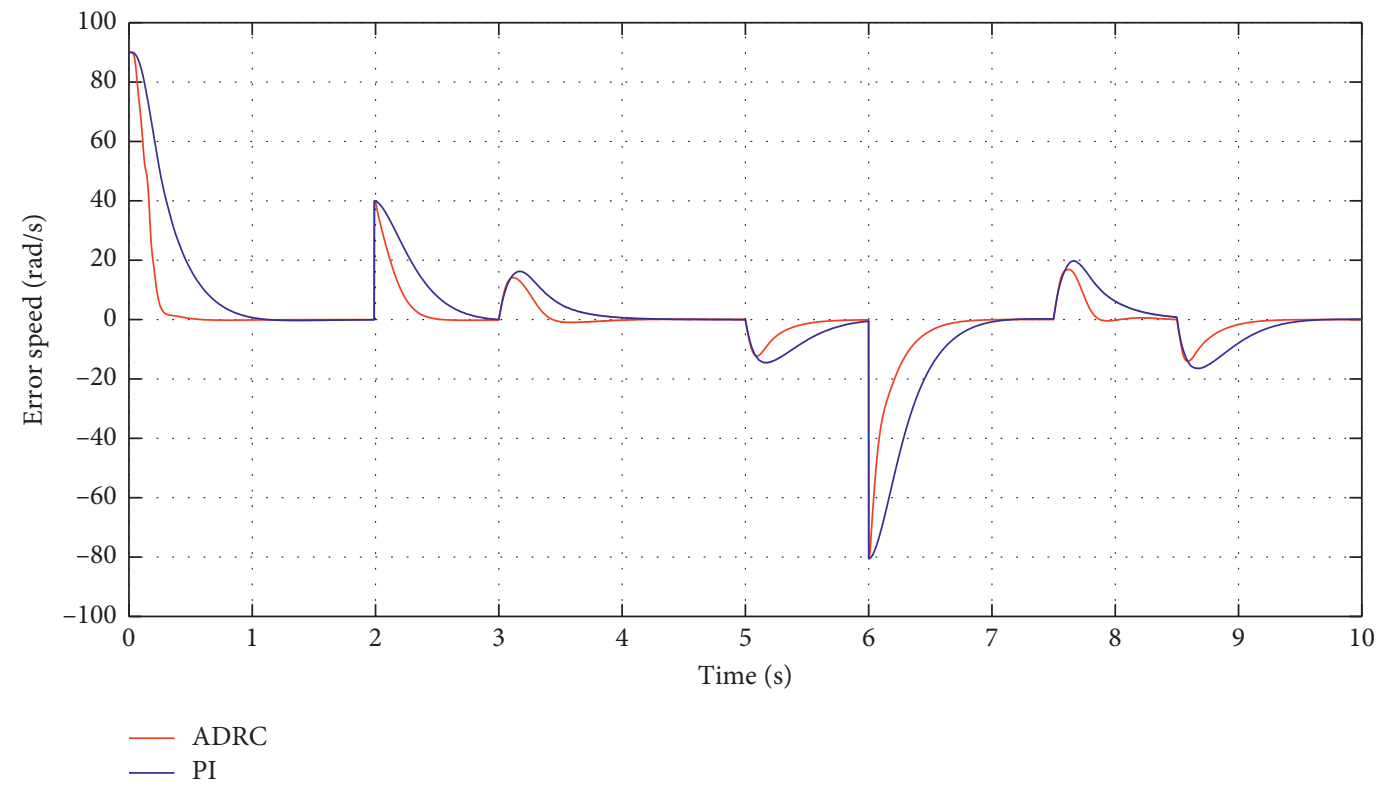

FIgURE 12: The result of error speed for PI and ADRC used in the sensorless control IM fed by FL-HBCI. 


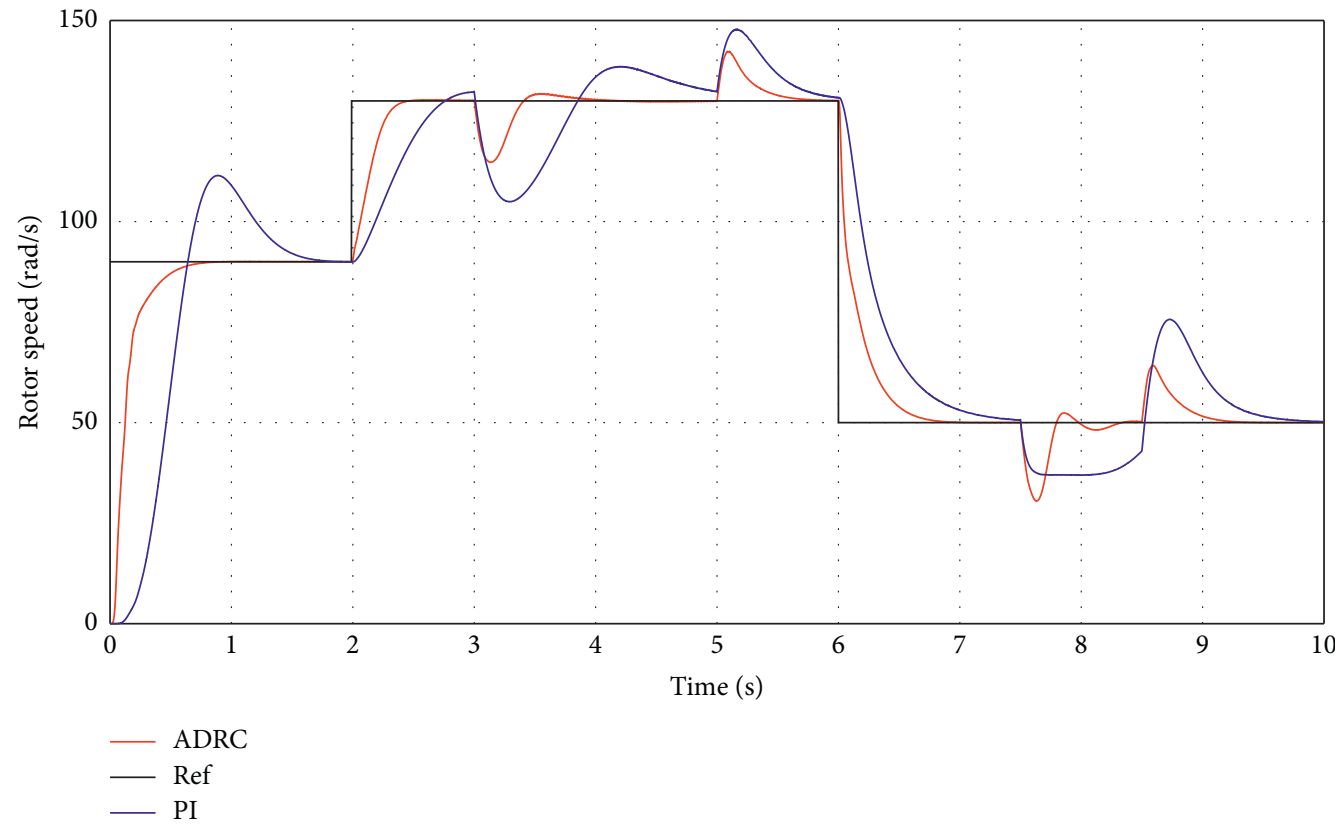

FIgURE 13: The result of rotor speed for PI and ADRC under rotor resistance.

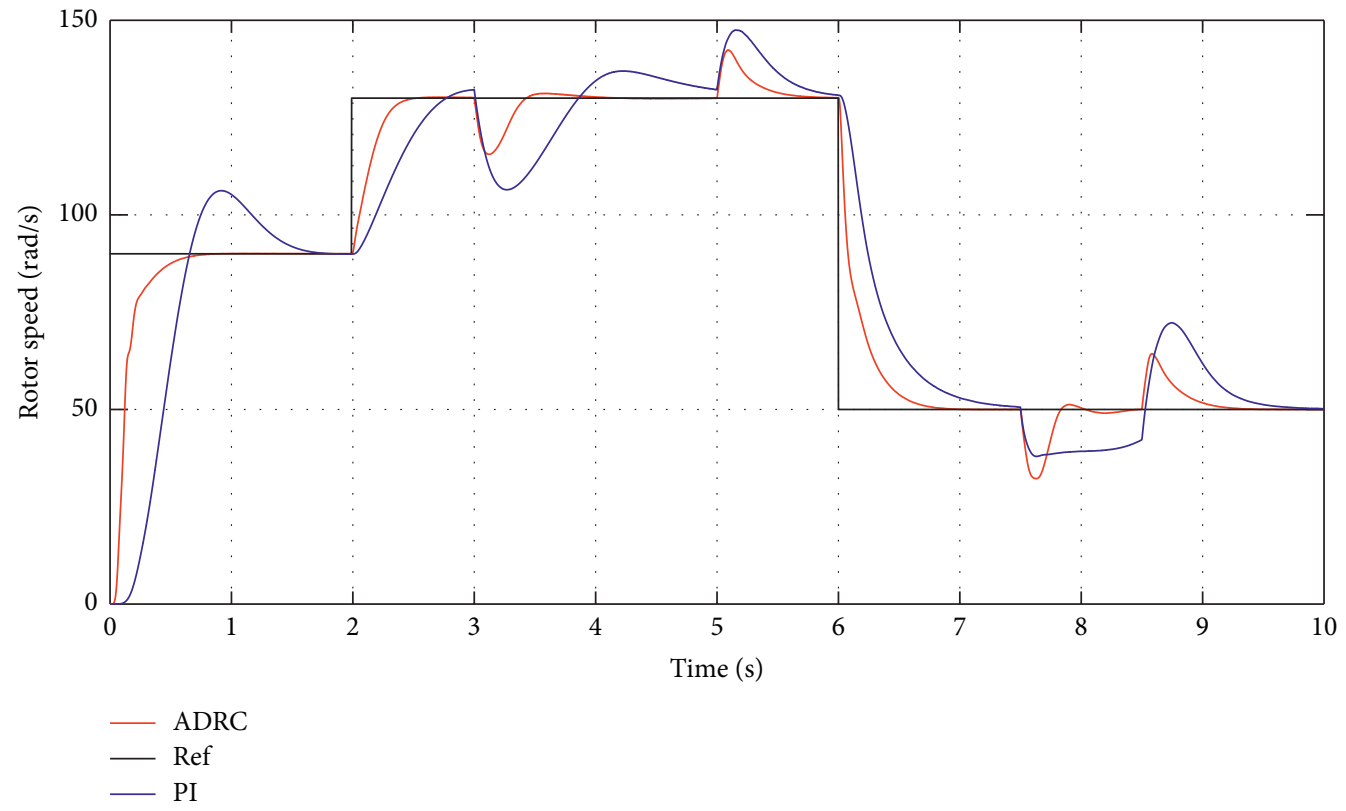

FIgURE 14: The result of rotor speed for PI and ADRC under stator resistance.

$0 \mathrm{~N}$ to $5 \mathrm{~N}$, the speed output has a smaller fluctuation with ADRC. Meanwhile, the rotor speed with PI takes more time to return to its steady state.

It can be noted from the simulation results that the proposed method with ADRC is more robust than the system with PI because it can compensate the disturbance caused by the variation of rotor and stator resistances.

\section{Conclusions}

In this paper, to improve the performance of the control, a vector control scheme sensorless was proposed for FL-HBCI feeding IM based on ADRC.

To compensate the external (the load torque) and internal (resistances variation) disturbances, the application of 
three ADRC to the system in sensorless vector control system has been proposed, instead of the PI controllers. The ADRC contains the ESO that can estimate and compensate the load disturbances and the sudden change.

The LO has been used to estimate the rotor speed. Furthermore, the FL-HBCI has been incorporated into the system to achieve the output with a minimum of losses.

From the simulation results, the proposed system makes the system more robust. Rapid response time and accurate output are achieved using the suggested control system.

The results also prove a high performance of the proposed solution and confirm that the system with ADRC is better and stiffer than the classical PI control under the different scenarios and disturbance conditions.

As a perspective of this work, we intend to compare the performance of the proposed method to the main existing methods.

\section{Data Availability}

No data used to support the study.

\section{Conflicts of Interest}

The authors declare that they have no conflicts of interest.

\section{References}

[1] O. Naifar, G. Boukettaya, and A. Ouali, "Robust software sensor with online estimation of stator resistance applied to WECS using IM," International Journal of Advanced Manufacturing Technology, vol. 84, no. 5-8, pp. 885-894, 2016.

[2] H.-C. Chuang, G.-D. Li, and C.-T. Lee, "The efficiency improvement of AC induction motor with constant frequency technology," Energy, vol. 174, pp. 805-813, 2019.

[3] Z. Guo, J. Zhang, Z. Sun, and C. Zheng, "Indirect field oriented control of three-phase induction motor based on current-source inverter," Procedia Engineering, vol. 174, pp. 588-594, 2017.

[4] G. Boukettaya, O. Naifar, and A. Ouali, "A vector control of a cascaded doubly fed induction generator for a wind energy conversion system," in Proceedings of the 2014 IEEE 11th International Multi-Conference on Systems, Signals \& Devices, SSD 2014, Barcelona, Spain, February 2014.

[5] A. Venkadesan and K. Sedhuraman, "Novel neural network based speed estimator for multilevel inverter fed sensorless field oriented controlled IM drive," Energy Systems, vol. 11, no. 4, pp. 909-933, 2020.

[6] D. Casadei, F. Profumo, G. Serra, and A. Tani, "FOC and DTC: two viable schemes for induction motors torque control," IEEE Transactions on Power Electronics, vol. 17, no. 5, pp. 779-787, 2002.

[7] T. Abdelkrim, E. M. Berkouk, K. Benamrane, and T. Benslimane, "Study and control of 5-level PWM rectifier-5level NPC active power filter cascade using feedback control and redundant vectors," Turkish Journal of Electrical Engineering and Computer Sciences, vol. 20, no. 5, pp. 655-677, 2012.

[8] E. R. Ramos, R. Leyva, G. Farivar, H. D. Tafti, C. D. Townsend, and J. Pou, "Incremental passivity control in multilevel cascaded H-bridge converters," IEEE Transactions on Power Electronics, vol. 35, no. 8, pp. 8766-8778, 2020.

[9] M. F. Kangarlu and E. Babaei, "A generalized cascaded multilevel inverter using series connection of submultilevel inverters," IEEE Transactions on Power Electronics, vol. 28, no. 2, pp. 625-636, 2013.

[10] A. K. Gupta and A. M. Khambadkone, "A space vector PWM scheme for multilevel inverters based on two-level space vector PWM," IEEE Transactions on Industrial Electronics, vol. 53, no. 5, pp. 1631-1639, 2006.

[11] A. K. Panda and Y. Suresh, "Research on cascade multilevel inverter with single DC source by using three-phase transformers," International Journal of Electrical Power \& Energy Systems, vol. 40, no. 1, pp. 9-20, 2012.

[12] J. Xu, Z. Wu, X. Wu, F. Wu, and A. Shen, "An improved phase disposition SPWM strategy for cascaded multilevel inverter," Mathematical Problems in Engineering, vol. 2014, Article ID 731574, , 2014.

[13] C. I. Odeh, A. Lewicki, and M. Morawiec, "A single-carrierbased pulse-width modulation template for cascaded H-bridge multilevel inverters," IEEE Access, vol. 9, 2021.

[14] V. Sridhar and S. Umashankar, "A comprehensive review on CHB MLI based PV inverter and feasibility study of CHB MLI based PV-STATCOM," Renewable and Sustainable Energy Reviews, vol. 78, pp. 138-156, 2017.

[15] S. E. L. Bourhichi and M. E. L. Adnani, "Indirect vector control of induction motor using a five-level cascaded H-bridge inverter," in Proceedings of the 2018 International Symposium on Advanced Electrical and Communication Technologies, pp. 1-6, Kenitra, Morocco, November 2018.

[16] P. Naganathan and S. Srinivas, "Direct torque control techniques of three-level H-bridge inverter fed induction motor for torque ripple reduction at low speed operations," IEEE Transactions on Industrial Electronics, vol. 67, no. 10, pp. 8262-8270, 2020.

[17] S. Guven, M. A. Usta, and H. I. Okumus, "An improved sensorless DTC-SVM for three-level inverter-fed permanent magnet synchronous motor drive," Electrical Engineering, vol. 100, no. 4, pp. 2553-2567, 2018.

[18] O. Naifar, G. Boukettaya, A. Oualha, and A. Ouali, "A comparative study between a high-gain interconnected observer and an adaptive observer applied to IM-based WECS," European Physical Journal-Plus, vol. 130, no. 5, pp. 1-13, 2015.

[19] A. Oukassi and S. Elbourhichi, "Sensorless indirect control of induction motor fed by a multi-level inverter with consideration of variation in rotor and stator resistances," in Proceedings of the 2020 7th International Conference on Electrical, Electronics and Information Engineering ICEEE, pp. 142-149, Antalya, Turkey, April 2020.

[20] S. Li, M. Cao, J. Li, J. Cao, and Z. Lin, "Sensorless-based active disturbance rejection control for a wind energy conversion system with permanent magnet synchronous generator," IEEE Access, vol. 7, pp. 122663-122674, 2019.

[21] H. Heidari, A. Rassõlkin, M. Hosein Holakooie et al., "A parallel estimation system of stator resistance and rotor speed for active disturbance rejection control of six-phase induction motor," Energies, vol. 13, no. 5, 2020.

[22] J. Li and Y. Zhong, "Robust speed control of induction motor drives employing first-order auto-disturbance rejection controllers," in Proceedings of the 2012 IEEE Industry Applications Society Annual Meeting, vol. 51, no. 1, pp. 712-720, Las Vegas, NV, USA, October 2012. 
[23] J. Han, "From PID to active disturbance rejection control," IEEE Transactions on Industrial Electronics, vol. 56, no. 3, pp. 900-906, 2009.

[24] Z. Gao, "On the centrality of disturbance rejection in automatic control," ISA Transactions, vol. 53, no. 4, pp. 850-857, 2014.

[25] H. Chalawane, A. Essadki, and T. Nasser, "Impact of increasing stator resistance on active disturbance rejection control based sensorless induction motor compared with a conventional Pi and fuzzy logic control," International Review of Automatic Control (IREACO), vol. 11, no. 5, pp. 217-225, 2018.

[26] J. Luo, L. Wang, and B. Liu, "Low-speed control of PMSM based on ADRC + FOPID," Systems Science \& Control Engineering, vol. 9, no. 1, pp. 73-87, 2021.

[27] F. Blaschke, "A new method for the structural decoupling of ac induction machines," in Proceedings of the Conference Record International Federation of Automatic Control, vol. 1, pp. 1-15, Dussesrdorf, Germany, October 1971.

[28] P. Jain and S. P. Deshmukh, "Design of three-phase five-level cascaded $\mathrm{H}$ bridge inverter with boost converter," International Journal of Electronics, vol. 108, no. 2, 2020.

[29] P. Mehta, S. Sahoo, and M. Kumar, "A fault-diagnosis and tolerant control technique for five-level cascaded H-bridge inverters," IET Circuits, Devices \& Systems, pp. 1-11, 2021.

[30] J. Kim, J. Ko, J. Lee, and Y. Lee, "Rotor flux and rotor resistance estimation using extended luenberger-sliding mode observer (ELSMO) for three phase induction motor control," Canadian Journal of Electrical and Computer Engineering, vol. 40, no. 3, pp. 181-188, 2017.

[31] Z. Kandoussi, Z. Boulghasoul, A. Elbacha, and A. Tajer, "Luenberger observer based sensorless indirect FOC with stator resistance adaptation," in Proceedings of the 2014 2nd World Conference on Complex Systems WCCS, pp. 367-373, Agadir, Morocco, November 2014.

[32] W. R. Abdul-Adheem and I. K. Ibraheem, "Novel active disturbance rejection control based on nested linear extended state observers," 2018, https://arxiv.org/abs/1805.00505.

[33] I. Aboudrar, S. El Hani, M. S. Heyine, and N. Naseri, "Dynamic modeling and robust control by ADRC of grid-connected hybrid PV-wind energy conversion system," Mathematical Problems in Engineering, vol. 2019, 2019.

[34] H. Laghridat, A. Essadki, and T. Nasser, "Comparative analysis between PI and linear-ADRC control of a grid connected variable speed wind energy conversion system based on a squirrel cage induction generator," Mathematical Problems in Engineering, vol. 2019, 2019. 